\title{
Biological Reactions to Dental Implants
}

\author{
Lucian Toma Ciocan ${ }^{1}$, Florin Miculescu², \\ Marian Miculescu ${ }^{2}$ and Ion Patrascu ${ }^{1}$

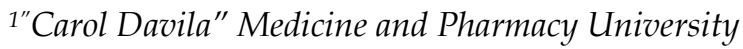 \\ ${ }^{2}$ University "Politehnica" \\ Bucharest \\ Romania
}

\section{Introduction}

Generally, the cells' isolated systems are more sensitive than the tissues of the body at the contact with material outside the natural system. Although, the research by applying some viable methods in vitro is constantly growing, because the cellular mechanism of the toxicity assessment materials can be described through some simple and cheep experiments, that could represent viable alternatives for testing in vivo on animals bio bases and, finally, on people. Using these testing methods, the materials can be classified according to their degree of toxicity and chosen, if necessary, for further testing in vivo. To appreciate the materials' biocompatibility for implantation in human body and to provide their functionality in vivo in the maximum safety for the patient represent a rigorous complex process, with two important distinct steps (Black, 1992): conducting preliminary assessment tests such as cytotoxicity, awareness, the irritant potential, intracutaneous reactivity, systemic toxicity (acute), subchronic toxicity (subacute), genotoxicity, implantation, hemocompatibility, or conducting tests for complementary evaluation, that consist in testing the chronic toxicity, the carcinogenicity, the toxicity of reproduction and development (growth) and the biodegradation.

Through the process of testing in vitro the biomaterials can be assessed in a number of functions and characteristics of cells, as: integrity of membrane, cytoskeleton, viability, proliferation, proteins synthesis, oxidative response, mobility, secretion, response to growth factors, cell-cell interactions. To prepare the materials for testing the cytotoxicity has a great importance, because those physical and chemical properties strongly influence the cells response and the entire experimental system. Testing standards and how to prepare samples for testing in vitro are present at all professional bodies, including International Organization for Standardization (ISO), Ente Nazionale Italiano di Unificazione (UNI), British Standards Institute (BSI), Deutsches Institut fur Normung (DIN), Swiss Association for Standardization (SNN), Association Francaise de Normalisation (AFNOR), American Society for Testing and Materials (ASTM), American Dental Association (ADA). In such a standard are presented the requirements for physical and chemical form of materials, sterilization procedures, form and size of samples and any treatment required to obtain a sample suitable for cytotoxicity testing. The adoption of these specifications is recommended when pursued some comparisons between different laboratories or when 
you need a report for a manufacturer; application of those standards among other things ensure that the material or its properties are not impaired by the procedure of preparation of samples for testing. In case of testing in vitro, solid materials are usually used when tested biomaterial surface affects the cell response clearly. In these cases, the combination of solid material - formed cell experimental system that reproduces the best situations arising in vivo. It is very important to know that only the mere change in form and the sample size studied can make the difference between obtaining as result a nontoxic effect or a very cytotoxic one (Brodbeck et al., 2001). Obtaining cell adhesion on biomaterials is considered a positive phenomenon in order to continue the test for studying the biomaterial behaviour after implantation. To assess cell adhesion to foreign surfaces is mainly used cell counting, and electron microscopy techniques and computer assisted measurements are used to assess the distribution and morphology.

\section{Materials and methods for evaluation}

The most popular standard of testing the biomaterials, ISO 10993, in the section dedicated to the in vitro tests (the $5^{\mathrm{ft}}$ part), does not specify the most important parameters for cytotoxicity testing, but only lists certain characteristics and properties that can be pursued during the course of the evaluation of biomaterials in vitro behaviour, to permit the research laboratories to determine their own steps to make on the cell type, duration of exposure, assessment method, etc. According to this standard, to be performed cytotoxicity tests must be met several conditions:

a. The tests must be performed on finished product or representative samples of the finished product or materials;

b. Choosing the testing methods must take account into:

- nature, extent, duration, frequency and conditions of exposure or contact with the human body surface in normal use devices provided;

- $\quad$ physical and chemical nature of the finished product;

- toxic potential of chemical components of the finished product formula;

- relationship between body size and device surface to which it is applied

- $\quad$ existing information based on literature, experience and clinical trials;

- $\quad$ protect humans and animals to perform experiments;

For the use in cytotoxicity testing of biomaterials are offered several types of cells and cell lines. At this point, it is still debated question of use in vitro testing fresh cells selected from explants, primary cells, or selected cellular lines. Likewise, it is not indicated the duration of cell exposure to materials / devices, as, generally, it is dictated by the test method applied, but it can be taken into account the average duration of implantation of the tested biomaterial. (Kilburn et al., 2003)

Currently, testing the cytotoxicity needs 24 hours, but, in many cases, this exposure can be diminished or extended. The duration of contact with the materials may be restricted to 1-2 hours, as it is recommended for the testing of some types of dental materials that will be applied to the oral mucosa only for a few minutes. This reduction in testing time in cell culture is because, having gone through a period of 24 hours of investigation can be obtained for a highly toxic material / device tested, which could lead to rejection due to raise awareness. If this material has unique properties and optimal performance in vivo short exposures, the benefit obtained by its use may be higher than the risk of patient. 
The ISO 10993 standard indicates that for testing the cytotoxicity "the assessment type is at free choice". The Standard are presented in four categories of assessment types, including which we find a cell morphology one and some measurements of cell parameters. The same standard is specified also that, for original cataloging of materials, methods adopted by the laboratory must be technically simple, reproducible, and applicable to a broad spectrum. The initial cataloging of biomaterials, cell viability, or the number of dead cells and to determine cell growth inhibition are common parameters. Using the assessment of these factors can be measured the tests' toxicity, as the biomaterials are classified according to their cytotoxic effect. Although their cell viability and growth are clearly defined, the distinction becomes less clear when it used the same test method to measure both parameters.

If cell growth, although time consuming, cell counting hemocytometer or Coulter counter is still widely used. The cell counting methods have a high risk of inaccuracy, mainly because of the steps needed to obtain cells in suspension, including repeated washing and cell transfer. Since there is no need for a transfer cell after contact with the biomaterial, the staining procedure of microplates cultures of cells is used to quantify their DNA's. Currently, dye fixing cell cultures are used substances such as amido black, crystal violet and methylene blue, later on being obtained the solubilisation of the cell adsorbed color, as the absorption of blue color can be measured with a specific wavelength of color used (Puleo \& Nanci, 1999).

The best demonstration of the ability of cells to grow in vitro in case of biomaterials testing consists of trying to form colony cells. The main limitation of this technique consists of the experiment duration: the results of an experiment can be obtained after two three weeks, since the materials that temporarily blocks cell division can be classified as cytotoxic if cells are prematurely processed. (Yan et al., 1997) To achieve ranking as cytotoxicity of biomaterials, it is necessary to apply quantitative methods. They are necessary also if biomaterials' cataloguing is required, but if it is imperative to have an answer for validation or invalidation of a product, while the morphological and qualitative methods provide important information, and can not dictate such a decision; qualitative methods can be used only to characterize the biomaterials. In the study of biomaterials' cytotoxicity should be measured the damages caused by them in cellular cultures, in order to define a limit of nontoxicity. The cytotoxic effect is expressed in terms of the proportion of surviving cells after the contact with the biomaterial; using the values expressed in percentages may be compared to the results of various test methods. (Dekker, 1994). In none of the documents mentioned above, any limit is established for estimating the maximum acceptable value of toxicity. Some authors classify materials as cytotoxic when the cell survival is less than $50 \%$ or $75 \%$, while others resort to statistics to detect a significant difference between the materials and tests. A material can be used clinically, even if it has a relatively high toxicity, due to a lack of valid alternatives. From this point of view, especially for clinical applications may be chosen the least toxic materials available.

By analyzing the cellular inhibition' growth induced by biomaterial and the cellular cycle of used culture, the toxicity' grade was expressed as percentage depending the cellular proliferation inhibition (CPI\%), by the formula: $\mathrm{CPI} \%=1$ when the number of sample cells/the number of control cells equalizes 100. Using CPI\%, 4 different levels of toxicity have been identified, namely: "high toxicity" (CPI\%=50), "medium toxicity" (CPI\%<50\% \& $>25 \%$ ), "low toxicity" (CPI\%<25\%) and nontoxicity (CPI\%=0). (Hazan, 1993). 
Currently, the apoptosis is detected by flow cytometry in most cases and only rarely by conventional electronic microscopy techniques or DNA electrophoresis site, which can be complementary techniques. The flow cytometry with complementary techniques such as optical microscopy, confocal fluorescence, scanning or transmission fully covers all the biochemical and morphological aspects that need to be taken into account in the biocompatibility of materials.

The release of high concentrations of implants and prosthetic components in the body, due to the occurrence of corrosion phenomenon, may favour the appearance of the necrotic phenomena and the inflammatory reactions of the surrounding tissue. However the release of these elements in the body may be followed by toxic effects, characterized by apoptotic phenomena: this situation is less serious, because the tissue adaptation to the implant is not seriously affected. In conclusion, although theoretically simple, the applicable to cellular culture tests to assess the biocompatibility requires a number of factor limits that are determined after a thorough analysis. As mentioned, the main items to consider include the preparation and handling of material, test methods and quantitative assessments. It is also very important the conclusion that the mechanism of occurrence of cell death induced by the material is uncertain, the final conclusions regarding the interactions between the biomaterials and implants or prosthesis can be explained by studying the reactions of tissues observed after in vivo implantation.

The compatibility with blood or the hemocompatibility materials and medical devices is determined by using uncurled blood (a major limitations of these test) and the evaluation of blood clots on the surface of test samples, and also the activation of the coagulation cascade, the adhesion of platelets, the complement system activation and the erythrocytes. Depending on the ultimate goal of biomaterial use, the hemocompatibility tests must be conducted in static or dynamic conditions. (Anselme et al., 2000).

The in vitro cellular culture models can be used to determine the effects of chemical compounds (the concentration of ions released during the corrosion of metals or molecules released during the degradation of polymers) on the body. The materials that do not meet the toxicity should not be further considered. Even if the materials pass the test of cellular culture, must be taken into account also the effects caused by the products resulting of degradation on cellular morphology, proliferation and other cell functions.

\subsection{Biomaterials in vitro testing methods}

As it has been previously described, the in vitro cellular culture models can be used in the preliminary assessment of biocompatibility of materials. As with other models, measures must be taken in interpreting the data correctly and avoid risks that may result from an incorrect extrapolation. Without doubt, these models are very useful in studying the cell functions, but still, this approach has its limitations. These results must be combined with those from in vivo tests to reveal all the aspects of biocompatibility.

Determining the safety of a biomaterial and its efficacy as a implanted device is finally made after its implantation on animals. Such studies, realized on an animal material correctly chosen, have been shown to be directly applicable in human subjects. The most biological processes, in particular wound healing, are also compatible. The specialized literature is replete with descriptions of animal models that were used to evaluate various materials and devices. Unfortunately, there are deficiencies in terms of the pathological data from the observations made on materials and implanted devices in human subjects. This deficiency is 
linked to issues of recovery and histological evaluation of an implanted device when a patient's death was not caused by its presence. The choice of an animal species relies more on its cost and / or availability than on the relevance for the human situation. As provided in the ISO rules, the first phase of testing a new material is best performed in a tissue culture. The second phase of testing for any application is the subcutaneous or intramuscular implantation in rodents, with a histopathological evaluation of the tissue that develops around the test material. If you want to use it for orthopedic purposes, the material should be implanted into the rabbit femoral intramedullary cavity. The animal model chosen for the third phase of the complete testing the device depends on its final application. (Ilin \& Skvortsova, 2002)

The ideal animal model should have many reproducible features to simulate an analogue or counterpart condition in which the material would find use in humans. The scientific criterion for selection of the animal model depends on the intention of applying the biomaterial. More specifically, should be taken into account the anatomical, biochemical, physiological, pathological and/or psychological characteristics. Over the years, it has been found through trial and failure that human systems resemble with different animal species. In addition to anatomic, pathologic and physiologic similarities with humans, that should be taken into account when choosing an animal model, the researcher conducting the experiment may be limited in choice, because practical considerations. The size and conformation of the animal may be one of the limits. The small animals cost less and are easier to handle. However, surgical procedures on large animals are easier to perform.

The bone healing and its reactions with biomaterials in goats, showed a similarity to those of humans on the type of cell, collagen structure, the structure of the soft and hard tissue, but also on the time of occurrence of the specific biological phenomena. In addition to management considerations, goats and sheep, as well as rats tend to develop ectopic ossifications in these structures, highlighting them as unviable models for researching the characteristics of artificial tendon healing. The rabbit represents an often test system used in Orthopedics. Even if an important part of special publications support the inadequacies of animal model in predicting similar behaviour of biomaterials implants in humans, it is still widely used. The reasons are probably more historical and economic. (Wennerberg et al., 2003)

The dental implants have been studied in dogs, monkeys, baboons and pigs. Although the specific anatomy of these species is quite different from that of human, the tissue responses to periodontal disease and gingival withdrawals are quite similar. This research area resembles Orthopedics.

The wound healing studies performed to observe the effectiveness of different treatments wounds are best performed on young domestic pig. The animals' use into laboratory for in vivo testing should be responsibly done and only after have been met the other conditions of preliminary biocompatibility, eventually after using computer simulation models and in vitro experiments. The main concern in using animals for in vivo testing is not to produce to the animal an unnecessary suffering or harm. Therefore, the researchers should carefully select the animals that will test and make a detailed planning investigation. All these things should be realized taking into account the national and international laws.

\subsubsection{Classification of in vivo tests}

The animal tests used to assess biocompatibility are classified into three main categories (Black, 1992): 
- The nonfunctional tests can be applied in various forms, the implants being usually inserting into the soft tissue (subcutaneous, intramuscular or intraperitonal) with minor incisions, or into the hard tissue, through the practice of geodes or resection of the femoral head and the insertion of intramedullary implants. These studies are of short duration (days to months) and provide valuable information about local interactions between the implant and surrounding tissue, data being obtained in the absence of mechanical loads.

- The ex vivo tests, as arterio - venous and vein - venous suture type, are used to divert a portion of the blood of an animal to a material, and back into the circulatory system. In this case, vital information for determining the blood compatibility to the used materials is the accumulation of proteins, cell adhesion and clots' formation on the material' surface.

- The functional tests involve implantation into the animal organism of some reduced scale prostheses, for example hip or heart prostheses implantation in similar conditions to those in the human body. These tests are lengthy; require special conditions regarding the design, production, testing of various types of prostheses, while being complex and expensive.

The use of materials for implants and medical devices applied on animals provide valuable information on the complex interactions that occur between the implant and the body, the chronic and acute inflammatory responses and all the problems throughout the process. It also can cause pyrogenic, immunological and toxicological animals' responses to implants. Detailing the methods and procedures is available in the specialized literature and publications of standards institutions. Compared to scientific standards, the medical evaluations should be carried out lawfully. Furthermore, in vivo and ex vivo tests must meet

\begin{tabular}{|l|l|}
\hline Location & Influence factor \\
\hline \multirow{4}{*}{ Material } & Chemical volume and chemical surface properties \\
& Surface roughness \\
& Superficial Porosity \\
& Superficial energy \\
& Surface charge \\
& Chemical and physical stability \\
& Chemical properties of degradation products \\
& The physical characteristics of breakdown \\
\hline \multirow{3}{*}{ Implant } & Size and Shape \\
& The elasticity mode / stiffness \\
\hline \multirow{5}{*}{ Host Organism } & Species (in animal experiments) \\
& Tissue type and location \\
& Age \\
& Genre \\
& General health \\
& Medications \\
\hline \multirow{3}{*}{ Implantation method } & Surgical techniques \\
& Fixing the tissue implant \\
& Infection \\
\hline
\end{tabular}

Table 1. Factors that may influence implant-tissue interaction (Black, 1992). 
the requirements of empowered institutions. After received the acceptance of these institutions, the medical devices can be implanted in a small number of patients that will be closely monitored.

In all cases of testing the biomaterials, the ethical considerations are very important. The identity of those who take part in these tests must be kept confidential. The animal tests can provide very important information about materials and medical devices, the tissues in which they have been implanted, but also the implant acceptance by human or animal body. To conduct practical experiments necessary to evaluate the interactions occurring at the tissue implant interface, we chose the rabbit as animal model study, because it is an often used animal for clinical studies, has enough dimensions and does not involve special surgical conditions, and the postoperative monitoring and maintenance costs are relatively low. (Moiseev, 2004)

By performing the implantation tests, it seeks global response, the result of the interaction between implant and host tissue, the role of the phenomena on the tissue implant interface. Their progress may depend on the properties and characteristics of volume and shape of the implant, and its surface roughness. Generally, by evaluating tissue reactions at the implant interface may be a distinction between bioinert, biotolarated and bioactive materials and also can get information on biofunctionality, biocompatibility, biodegradation, and bioactivity. The overall response of the body, considered as a measure of biocompatibility is determined by reference to the factors presented in Table 1.

\section{Experimental study on tissue biomaterial interaction}

\subsection{Determination of chemical composition of biomaterials}

The first step in evaluating any biomaterial, metal or not, is up to the identification and characterization in terms of its chemical composition. Currently, it is available for conducting such investigations a variety of compositional characterization methods. To make the characterization in terms of chemical composition, the research presented in this paper, we used the following energy spectrometry (EDS), method that allows the materials assessment with sufficient precision for characterization and classification of selected biomaterials into specific ASTM standards groups. For the study of the interactions that occur at the interface implant tissue to cover as wide a range, we selected the most representative class of biomaterials and used metal groups, as follow: commercially pure titanium, titanium alloy Ti6Al4V type, CoCrMo alloy, and austenitic stainless steel to a medical purpose. The quantitative chemical determinations made by EDS spectrometry have allowed cataloging tested materials, see Figure 1, and their classification in terms of the compositional type in ASTM marks of the biomaterials. To avoid the phenomenon of contamination of samples, they were cleaned by ultrasonic in methanol at $50^{\circ} \mathrm{C}$ for 15 minutes and then doubly distilled pure water at $90^{\circ} \mathrm{C}, 30$ minutes and dried in hot air.

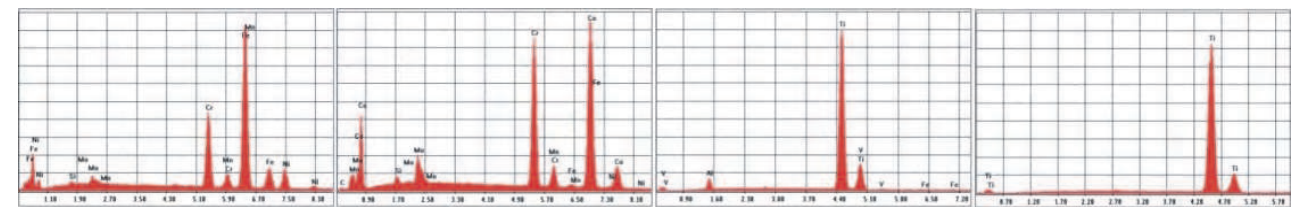

Fig. 1. EDS spectra characteristic chemical compositional analysis of the main classes of metallic biomaterials. 
The experimentally determined values are within the limits imposed by ASTM standards, in the following classes: commercially pure titanium covered in ASTM F67; Ti6Al4V alloy type fall in ASTM F136; CoCrMo alloy type fall in ASTM F75; Type 316 austenitic stainless steel covered in ASTM F138.

\subsection{Micro structural characterization of metallic biomaterials}

The characterization of biomaterials in terms of micro is a particularly important factor in the interaction of the implant tissue interface due to at least three respects:

- corrosion resistance of biomaterial is correlated with its microstructure;

- microscopic surface inhomogenity, such as crystal grain boundaries or secondary phase precipitates, could be important in protein adsorption on metal surfaces uneven;

- formation of mineralized bone tissue is dependent on bone cells' activity, activity influenced by the superficial topography of the substrate.

The existence of conflicting results in terms of material influence on short-term interactions between bone cells and the various surface layers, may have as a possible explanation the fact that the correlations between various factors that manifest themselves such as umectability and topography of the substrate surface, respectively, the chemical processes at the interface implant biological environment. At a microscopic scale, the surfaces of biomaterials can act differently. On the surface of the biomaterials, can be portions or areas of different functionality, and they may interact differently with biomolecules. For example, many metallic biomaterials contain at least two different phases. Not only that reacts differently with molecules of different phases, and grain boundaries behave differently from the middle of grains. (Smith et al., 1992)

The selected samples were directly analyzed by light microscopy for evaluation according to ASTM standards for each biomaterial in part, in terms of the incluzionary status. After evaluation and compliance with standards in this regard, the samples were subjected to the metallographic attack by chemical reagents specific for each material. Whenever necessary, the metallographic attack was carried out electrochemically. Due to limited space, this paper presents a few representative images (see figure 2).

The sample type 316L austenitic stainless steel was obtained by implementing the solution hardening $\left(1050^{\circ} \mathrm{C} /\right.$ water $)$ and plastic deformation at cold, with a degree of deformation of $30 \%$. The chemical composition of type 316L steel falls within ASTM F138 limit, the determined percentage of molybdenum $(2.19 \%)$ is to the lower limit, thus ensuring a low tendency of formation of $\delta$ ferrite. In the chemical composition of this steel, copper has not been detected (detection limit of copper by EDS method being $0.1 \%$ by weight), which is recommended by ASTM standard F138. The percentage of nickel located at the lower level $(12.33 \%)$, in conjunction with a sufficiently low percentage of manganese $(1.79 \%)$ led to the avoidance of appearance of the $\delta$ ferrite traces according ASTM F138. Metallographic speaking, the standard recommends the lack of the $\delta$ ferrite phase in its structure and also the average of the grain size not exceeding 5, which is a dimension of the grain size with a high degree of uniformity, less or equal than to $100 \mu \mathrm{m}$. In accordance with the quantitative analysis obtained by the Underwood method (interception method), it has result a grain size according to ASTM E112, of 11.0, which shows a much smaller grain and more uniform than the maximum permissible value in the standard. The structure consists of austenite grains, relatively deformed in longitudinal section and stronger macle than the cross sectional. Following electrolytic attack, both in longitudinal section and cross-sectional, deformation 
lines can be observed, where the attack occurred more stressed, which is obvious what is noticed in the images obtained through interferential phase contrast. The lack of compounds (carbides of $\mathrm{Cr}$ and $\mathrm{Mo}$ ) in the structure leads to the assertion that the heat treatment of hardening of formal solution $\left(1050^{\circ} \mathrm{C} /\right.$ water) was well chosen and leaded. The hardness determinations have been registered a medium value of $341 \mathrm{HB}$, which complies with the requirements of ASTM F138.

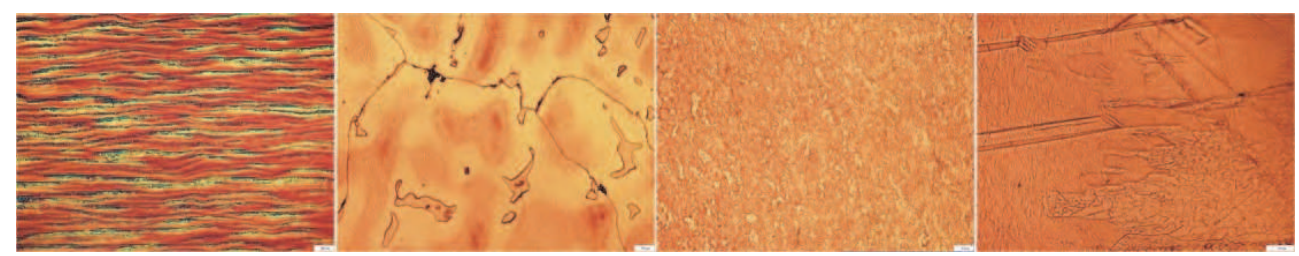

Fig. 2. Bright field optical microscopy images on the analyzed samples surface (from left to right - 316L austenitic stainless steel type, CoCrMo alloy type, Ti6Al4V and CP Titanium).

The examined CoCrMo alloy fits the ASTM F75 standard, both in terms of chemical composition and structural point of view. The able cast microstructure consists of a matrix rich in cobalt, alpha-phase strongly segregated, with interdendritic and limit grain separately compounds. These compounds are mainly formed with one of the carbons: $\mathrm{Co}$, $\mathrm{Cr}$ or Mo (which is according date of the specialized literature). (Stanford et al., 2003) Carbide content may decrease the same time with a homogenization of alpha phase, by thermal annealing treatment later realized. According ASTM F75, strength criterion in selecting material for use in making medical implants is not recommended to be important for its rejection. The area occupied by a grain is about $4 \mathrm{~mm}^{2}$, the dendrites' orientation in the grain is predominantly by the grain growth direction. The samples were taken from a $30 \mathrm{~mm}$ diameter ingot, which is why, because the relatively low speed of solidification, the grain size has large and irregular values. For the characterization of dendritic structure, it has been made measurements of the distances between their axes, resulting in values of maximum $86 \mathrm{~mm}$ and minimum $4 \mu \mathrm{m}$.

The Ti6Al4V alloy samples type "ELI" (Extra Low Interstitial) were plastically deformed by hot rolling at $900^{\circ} \mathrm{C}$ heat treated at $720^{\circ} \mathrm{C}$ for one hour / air cooling. The resulting structure consists of elongated grains of alpha phase, light, in a matrix of transformed beta phase. Alpha ASTM F136 is finely dispersed, as is the beta one. The Alpha phase is slightly distorted plastic, and the resulting structure after heat treatment is a typical one, which has been taken into account the temperature "beta transus". The quantitative microscopy studies have led to the identification of a score of the grain size of about 12, which shows a degree of advanced finishing the grain size, using the same analytical method as previously investigated biomaterial; this score has a direct effect on increasing resistance to fatigue of the material. The inclusionary state was characterized by measuring the length of the inclusions, resulting in minimum values of $1.44 / 1.07 \mu \mathrm{m}$ and maximum $37.87 / 14.25 \mu \mathrm{m}$. In terms of distribution, it is noted that over $70 \%$ of the inclusions have a size smaller than $4.7 \mu \mathrm{m}$. The average area occupied by inclusions is about $1 \%$, which is an inclusionary state falling standard. The commercial purity titanium has been used to perform experiments covered in ASTM F67 standard and in terms of chemical composition of interstitial content elements that affect decisively technological and operating characteristics is corresponding to the three grade/level. The used biomaterial is in plastic deformed state, with a strain of 
about $30 \%$, the grains having diameters between 10 and $100 \mu \mathrm{m}$, which is consistent with moderate plastic deformation undergone material; the grain size was determined by computerized quantitative analysis, ASTM E112 - Underwood interception method, resulting in a score equal to 11. Also, in the grains that have suffered a stronger deformation, it is noted the presence of slip lines parallel and straight, specific to the compact hexagonal crystallization system, characteristically of this metal; otherwise, it has also been the order of surface corrosion prepared by the attack of the Kroll reagent, used to highlight the structure: parallel slip lines, grain boundaries and ultimately subgrain limit.

\subsection{Corrosion resistance of biomaterials evaluation}

Based on current knowledge, it is impossible to provide the behaviour of metallic biomaterials in the biological environment, unlike to providing corrosion behaviour of metals in an inorganic fluid. Also, it is very difficult to track the details of the in vivo experiments or in real time. Most times the obtained results represent a collection of snapshots realized under very different conditions. The appreciation potential of the electrode and the variation in time can be determined by the corrosion resistance of a biomaterial. Based on the records can draw variation diagrams of stationary potential in time. A comparative study of curves obtained for the four metallic biomaterials (see figure 3), previously characterized micro structural, reveals that, in terms of stationary potential value, the most electropositive (so the best in terms of general corrosion) is titanium, followed in descending order of Ti6Al4V alloy type, alloy type 316L austenitic stainless steel, and CoCrMo alloy. Studying the potential variation over time, it notes that the first two alloys are stabilized by a relatively small active area, the potential remaining stationary and not representing sudden changes that indicate some form of localized corrosion.

Larger active zones present 316 and the CoCrMo alloys, but steady change in the potential of the two alloys is different in time. Thus, stainless steel has a stable and more electropositive steady potential in time, while in case of CoCrMo alloy (cast) occur sudden changes of the potential. These variations have as the main cause the presence of casting

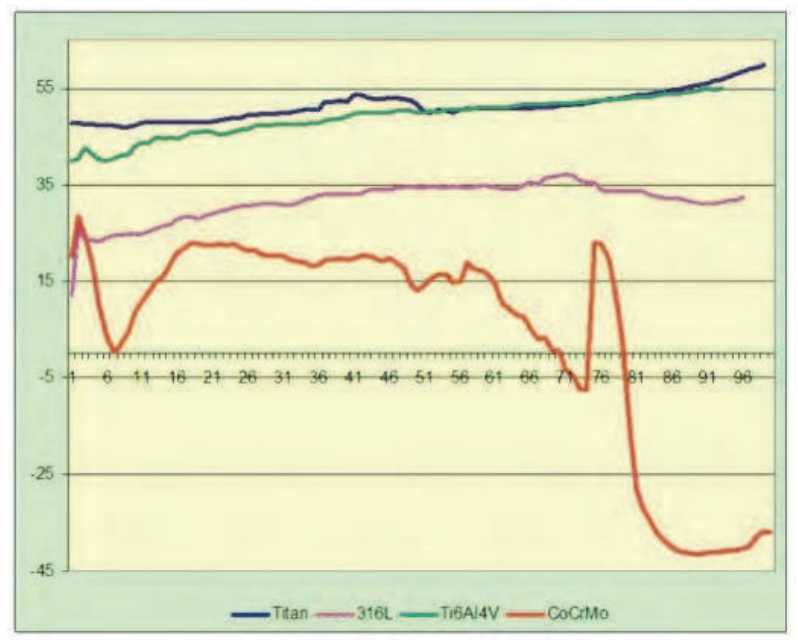

Fig. 3. Tabulated results of benchmark tests for stationary potential variation over time. 
defects. A comparative study of the corrosion cycles indicates that all the alloys present a field of passivation, but the value curve of passivation and the potential area in which appears this field is different.

The lowest intensity of corrosion and passivation current is presented by the titanium. In the case of CoCrMo alloy, which despite having a potential range of passivation current lower, both current corrosion intensity and current passivation intensity are below that of Ti6Al4V alloy and steel 316L, the latter showing values of these parameters higher than those of other materials. In the case of titanium and titanium alloy, the surface is unaffected by corrosion. In the case of type 316L stainless steel immersed surface is frosted, and with points of corrosion. The analysis of the distribution of chemical elements in a direction, the wren area, shows a decrease in iron concentration, in that area is identified chromium oxicarbure, which confirms the results of tests of the same type presented in the specialized literature. The CoCrMo alloy, after corrosion test, also shows a frosted surface on which it can be observed the presence of corrosion products with different shapes and morphologies. At the core configurations, molybdenum corrosion is found, surrounded by chromium carbide. The emergences of these formations that allow the release of large amounts of alloy elements contained in the test environment are due to obtain the worst results in terms of corrosion resistance.

Through the assessment of the corrosion tests, very important results have been achieved for the study of biomaterial - biological environment interaction, which fully comply with the data presented in the specialized literature and provide us a first qualitative ordering of classes of the studied metallic biomaterials (Miculescu et al., 2007). Thus, in descending order in terms of corrosion resistance, we can arrange biomaterials as fallows: commercially pure titanium, titanium alloy Ti6Al4V type, austenitic stainless steel, CoCrMo alloy respectively, results correlate with those obtained from microstructural measurements, which can be seen, in contested areas, the presence of the generating compounds of specific forms of corrosion. The bridging the electrochemical tests by scanning electron microscopy imaging and EDS microanalysis is an important factor in further developments of research because it provides certainty of correctness and validity testing.

\subsection{In vitro evaluation of metallic biomaterials cytotoxicity}

By using cell culture techniques, it can cause lysis (death) of cells, cell growth inhibition, and some specific effects on cells caused by the devices, materials and / or their extracts. By in vitro testing of biomaterials we can appreciate a number of functions and characteristics of cells, such as membrane integrity, cytoskeleton, viability, proliferation, protein synthesis, oxidative response, mobility, secretion, response to growth factors, cell-cell interactions.

For cytotoxicity testing of the shown biomaterials, we have prepared polished samples as disks with $5 \mathrm{~mm}$ diameter and $2 \mathrm{~mm}$ height. The purpose of processing in this manner is to ensure the unity of biomaterials surface reaction, without surface roughness becomes a factor influencing the behaviour of cell culture. After preparation, biomaterials have been cleaned with organic solvents and washed with distilled and doubly distilled water to eliminate any possibility of foreign elements or metal ions that come into reactive contact with the analyzed materials. Afterwards, the materials were subjected to dried sterilization at $1800^{\circ} \mathrm{C}$ for one hour, being manipulated in sterile conditions. The elaborated and used experimental models have persuaded the possibility to realize some multifactorial and monofactorial analysis which allow the correlation into a unified system of the needed results to evaluate the implantable biomaterials quality and the effect on the biological 
environment. Determining the influence of various metal samples above the fibroblast culture has been done by direct observation using the optical microscopy.

In the short term cytotoxicity tests, it was used a VERO cell line containing fibroblast-like cells. Cells were seeded in sterile polymer plates with a density of 600,000 cells / well. The cells were grown like in some evolving cultures of the monolayer Eagle environment, Dulbeco modified (DMEM), supplemented with 10\% fetal bovine serum (FBS) and with added antibiotics (PSN). The atmosphere in the cell culture chamber was 5\% CO2 in humidified air. The extraction test (MEM) maintained the report between the outer surface of the material and fluid volume (average) and was constant in all series of materials placed in the experiment. After harvesting the environment (MEM), 2 - 3 washes were done with FBS, pH 7.2 and then were fixed in methanol for 23 minutes at $4^{\circ} \mathrm{C}$. $10 \%$ Giemsa stain was used for staining. The evaluation of cell cultures was performed at 24, 48, 96 hours respectively. After completing 96 hours of the cell culture' development, the metal samples were taken from the culture plates, then they were washed with FBS and fixed in $0.1 \mathrm{M}$ phosphate buffer, to analyze them by light microscopy and scanning electron microscopy, so we can evaluate the follow parameters: monolayer confluence, cells floating degree, morphological changes. The percentage growth inhibition was determined by counting the cells, and the measurements were corrected for control with a negative filter. As a reference experiment, we took a fibroblast culture in which no metallic sample was immersed, the culture being kept under the same conditions of the experiments in which were immersed metallic samples.

The optical microscopy images (see figure 4), during light phases' contrast, have aimed the cellular culture at the limit between cellular culture and immersed sample. At all the studied experiments, a cellular monolayer was obtained, without being registered any free spaces, in which fully lack the cellular culture. In the case of the cellular culture without metallic sample (blank), the fibroblast cells of the culture highlight morph-structural fairly uniform characteristics. Covering the well with cellular formation is about $90 \%$, being obviously the cells' compaction and the appearance of the phenomenon of forming a multilayer culture.

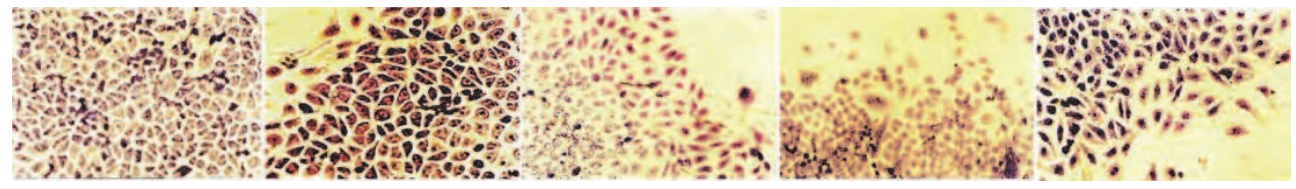

Fig. 4. Cell culture optical microscopy image of the analyzed samples (from left to right blank, CP Titanium, Ti6Al4V, CoCrMo alloy type and 316L austenitic stainless steel type).

Maintaining the titanium in the presence of the fibroblasts has as result a normal behavior of cells development and a positive chemotactism/chemo attraction related to the material, expressed through the migration and adherence of cells to its surface. The cellular culture joins and forms monolayer, considered as a clear indicator of a favorable biomaterial cell interaction. It can be observed flattening of cell shape and appearance of the cytoplasm emissions which prove the adherence and movement on the biomaterial surface. Significant is the tendency to establish intercellular contacts through extensions, gradually becoming close contacts and cells forming a single compact layer. In all cases, the cells have normal appearance with kernel and obvious nucleoli, the cytoplasm is dense and rich in cellular organelles, and the peripheral cytoplasmic area leads to monolayer formation. This 
area, with recognized vesicles in the cytoplasm, shows an intense functional activity, related to the synthesis and secretion of active substances that are necessary for the cells to migrate and establish the implant and other cells interrelations. Covering the studied area with cells is about $85 \%$.

The fibroblast cultures maintained in the presence of Ti6Al4V alloy sample has coverage of $75 \%$ of the well area in which the study has been made. The fibroblasts morphology is still normal, the cell-cell and cell-biomaterial attachment being high. The cells' orientation towards the immersed sample in the fibroblasts culture confirms the results presented in the specialize literature on the increased biocompatibility of this alloy. (Futami et. al, 2000)

The cellular culture aspect studied in the presence of the sample made of CoCrMo alloy type is uniform and lighter, covering the well with cells being about $65 \%$, similar to the results presented by many authors. (Puleo \& Nanci, 1999). The cellular culture compactibility is hight till an appreciate distance from the biomaterial, in its closures being observed a small number of cells uniformly dispersed throughout the perimeter samples. Sample type 316L austenitic stainless steel has a high degree of toxicity, comparatively with other cells, the fact being highlighted by a reduce cells viability, confirmed by the specialized literature (Kocijan et al., 2004). Even though cell layer density represents approximately $55 \%$ from the analyzed surface, the fibroblasts' morphology is normal and uniform. The cells' attachment is manifesting also on the cell-cell interface, but on the biomaterial-cell interface. Finally, depending on the studied biomaterial type, we obtained the monolayer formation which had varied from 90 to $55 \%$ of the surface, in some cases, being noticed the pluristratification trend.

Watching the cellular culture in vitro tests during 96 hours of investigation, in witness and parallel groups in the presence of the metallic samples, demonstrated the evolution of evolution of cell populations in percentage of proliferating, mobility and adhesion which, even though they had presented some variations, were within general acceptable biocompatibility terms. Obtaining these results can be correlated with the release of ions and particles in the structure and composition of the material in the environment, which would be consistent with the results of corrosion tests. It was also noted that the fibroblasts reached the level of metallic biomaterials surfaces generally tend to migrate onto those surface, and the function of intercellular adhesion is slower (inhibited). The results experimentally obtained are similar to data of the specialized literature where it is presented the same order of the metallic biomaterials' cytotoxicity. (Brodbeck et al., 2001).

\subsection{In vivo nonfunctional studies on animals}

The implant surface structure has a significant influence, both for joining tissue and the strength of adhesion to tissue. As this force is defined as a fraction of the pressing force of the area on which it is exerted, loading in real conditions may be even greater as the surface area is bigger. From this simple consideration, it is clear that a soft surface of the implant, with small area of contact with tissue, presents a lower adhesive strength than a structured surface. The biomaterials' surface properties are commonly grouped into three categories: geometric, chemical and electrical. Geometrically speaking, the substrates with more pronounced topographical features will exhibit a bigger surface for the interaction with proteins.

If it should be used an implant which geometry included angles and edges, the interaction between it and the biological tissue would be influenced, because undesired tensions would 
be introduced into the system. To avoid such problem we got implants with rounded edges. Since the rabbit is a relatively small animal, the implants were proportional, but with sufficient large areas that provide qualitative information and allow the production of normal phenomena and processes for such experiments. Given that the chemical, topographical, mechanical and electrical properties can affect the interaction between proteins and cells with the material, it requires a careful characterization of the surface.

The interaction of the intraosseous and intramuscular metal implants is influenced by their chemical composition and surface roughness. The design shape and size of implants was carried out primarily at obtaining nonfunctional specimens with surfaces that offer the possibility to investigate after conducting biological sampling, with many different preparation degrees in terms of roughness and smallest dimensions as possible, so the in vivo test could be done on small animals, cheep, easily maintained and monitored after surgery.

In vivo research undertaken on animals has focused on two areas:

- The processes evolution of osseointegration of titanium implants, goal in which have been made three samples of $99.99 \%$ pure titanium, metal considered by the specialized studies, as first on the biocompatibility scale, the samples having the parallelepiped shape with equal sides $2,5 / 2,5 / 5 \mathrm{~mm}(\mathrm{~L} / \mathrm{l} / \mathrm{h})$ transcortical implanted in the femoral head of three adult rabbits, according to the ISO 10993indications;

- Osseointegration of metal implants by the degree of surface preparation; of human functional prostheses were made rectangular samples with dimensions above mentioned. Each axial face of the sample was prepared by grinding on emery paper of different roughness: P1000 (metallographic polishing), P800, P600 P320 respectively. The samples thus prepared were transcortical implanted in the tibia same subject, an adult rabbit.

Before the implant, the samples prepared by the above methodology were sterilized with $\gamma$ ray to be biological measured, also being ensured their protection until the implant surgery. To achieve the surgery, it had opted for the rabbit's tranquilization with $1 \%$ Vetranquil, followed by general intramuscular anesthesia by administration of $5 \mathrm{mg} / \mathrm{kg}$ body of Ketamine. This administration was performed before preparing the operative field and about 15 minutes before surgery.

After the antiseptization and isolation of the operative field, it was performed a longitudinal incision along the antero-medial face of the calf for about $4,5 \mathrm{~cm}$. With the Pean forceps The Pean forceps the tegument was taken off till the muscular plane level obtaining two flaps "envelope" on both sides of the incision line.

After exposure and longitudinal incision of the tibial cranial muscle fascia, the site had been penetrated, with a Pean forceps, perpendicular to the muscle plan till the bone plane, among the fibers of this muscle. Selling the forceps' arms and its removal permitted the access towards the anterior medial tibia. After the dezinsertion of the muscular fibers the periosteum was taken off, exposing the diaphy bone plate up to the cranial epiphysis. At this level, with the help of rotary instruments at a speed of 5000rpm and under continuously irrigation with saline, are created the geodes, with shapes and sizes about equal to those of the transverse surfaces of implants. The implants are perpendicular inserted in geodes, by percussion. After hemostasis, the wounds are sutured with catgut wire in deep planes and with synthetic yarns in tegument plane.

The antibiotic prophylaxis was realized according standard norms, in unique doze, with cefazolin (cephalosporin generation I) - Lyzolin, which had been intramuscular 
administrated $50 \mathrm{mg} / \mathrm{kg}$ body 30 minutes before the surgery and 6 hours after surgery. 10 days after surgery, the sutures wires were removed.

\subsubsection{Biological material sampling}

The sampling was realized by sacrificing the subjects, at 2, 4 and 6 months after implantation (titanium implants), 2 months respectively after implantation (the type Ti6Al4V alloy and austenitic stainless steel type 316L) (see figure 5). To be investigated, the samples had been kept 6 hours in saline, had been fixed with 30\% glutaraldehyde solution, after that being rewashed with normal saline and ultra pure deionized water, in order to remove organic particles resulting from the soft and hard tissue sectioning.
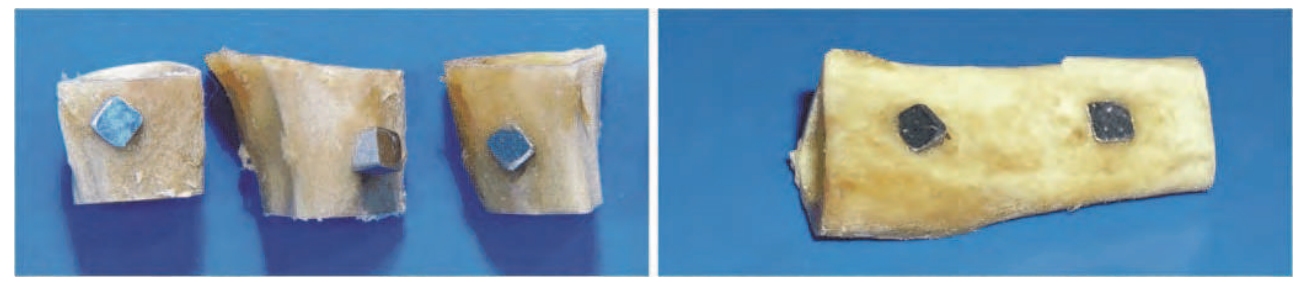

Fig. 5. The biological materials aspect after sampling: left-Ti 99,99\% at 2, 4 and 6 months after implantation; right Ti6Al4V and 316 respectively, two months after implantation.

\subsubsection{The osseointegration process evolution of the titanium implants}

It was analyzed the morphology and topography of the periimplantary bone surface under which it could be systematized the gradual evolution of biological osseointegration processes of the titanium implants. There has been initially formed a periimplantar blood clot from the blood derived through the interruption of the continuity of the haversiene vessels from the edge of the bony defect created by drilling. This blood clot consisted of the figurative elements of blood (erythrocytes and platelets) situated in eyes of network or mesh of fibrin. The elements observed and described through the ESEM images demonstrate the existence of a complex process of periimplantar healing. In the neighbouring tissues of the implant, there are initially produced modifications of the inflammatory type represented by hyperaemia, plasmexodia and formation of a leukocyte and macrophagocyte infiltrate.

Alike bone fracture healing, in the peri-implant healing the blood vessels are damaged, and this results in haemorrhage and the formation of a blood clot, or hematoma. In the bone fracture healing the amount of blood loss from the circulation depends on the location of the fracture. In the femoral shaft, up to one litre of blood can be lost due to extravasation (Cormack, 1987) whereas the amount lost in dental implant placement is significantly less, with the healing site volume measured in millilitres (Davies, 2005). A few days after the implantation, a proliferation of two types of cells become visible: the fibroblasts that will form a periimplantar fibrous callus and endothelial cells that will generate a capillary network of new-formation observed by ESEM as a periimplantar vascular plexus (see figure 6).

This periimplantar well developed vascular network appears to be the result of the angioformation activity of the bone red marrow from the spongious bone. According other studies, angiogenesis is initiated predominantly from post-capillary venules, where endothelial cells degrade the subendothelial basement membrane and migrate and 

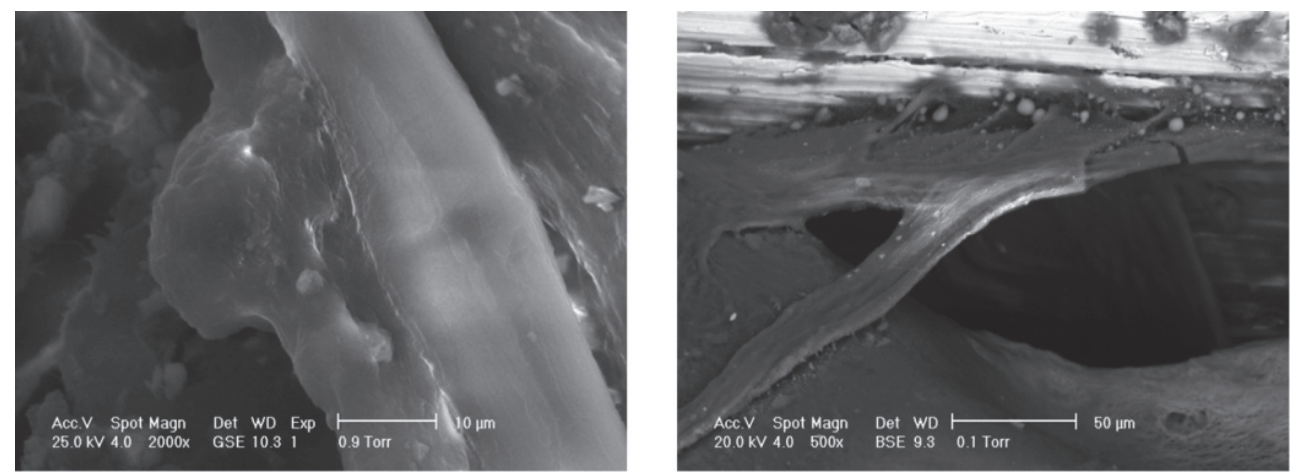

Fig. 6. Left - Extravasation of a blood cell at the level of the periimplantar bony tissue; right ESEM microscopy image of the peri-implantar vascular plexus.

proliferate to form hollow capillary buds or sprouts. We now know a great deal concerning the molecular mechanisms of angiogenesis, (Lakey at al, 2000) but, at present, we still do not know how the patterns of angiogenesis may be affected by the presence, or surface design, of an endosseous implant, although some attempts have been made to image the vasculature that develops around endosseous implants. (Murakami, 1995;)

Interestingly, (Matsuo et al., 1999) showed some differences in the neovasculature in cortical bone around machined and plasma-sprayed implants that exhibited distance osteogenesis. Other works (Davies, 2005) has also demonstrated that implant surfaces, which are known to promote contact osteogenesis, also exhibit a richer immediate periimplant vascular supply within the healing compartment. The apparition of the neoformation vessels appearance is an important moment of the healing due to the fact that the bloodstream within periimplantar rennet being accomplished, it becomes possible both a number of cellular changes and the acceleration of the metabolism. Our observations showed that through the processes of proliferation of fibroblasts and vascular endothelium, the periimplantar clot is replaced by granulation tissue during 14 days from the surgical
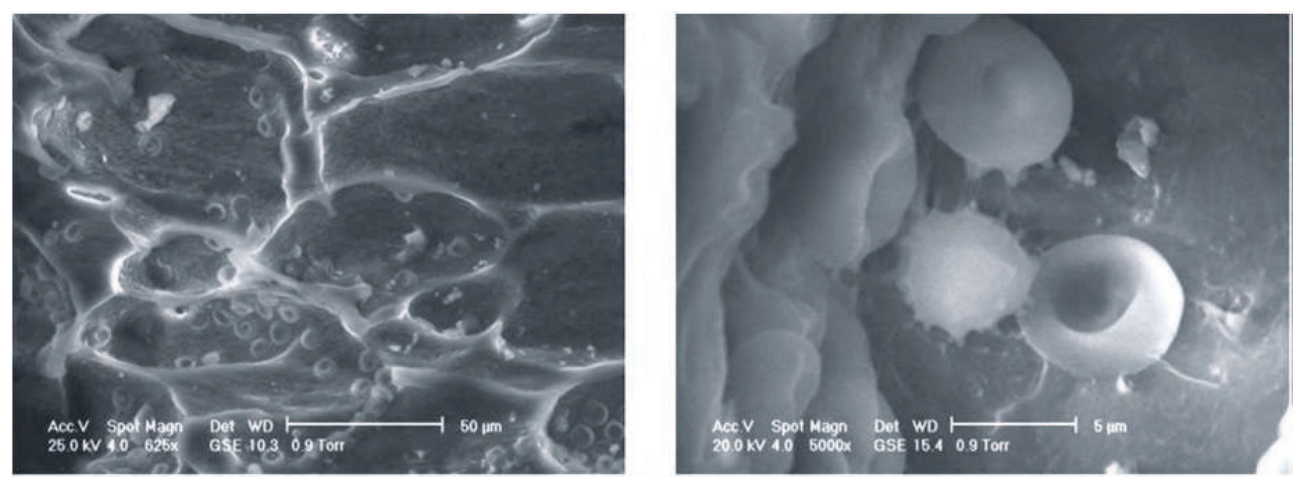

Fig. 7. ESEM image of the mature spongious bone tissue at the edge of bone defect created by drilling: osteoide trabeculae which delimit areoles filled with marrow blood tissue (left); platelets and hematite cells (right). 
procedure. At the same time, a process of osteoclasis resorption at the edges of bone defect begins. ESEM technique, the unconditioning of the preliminary preparation of the biological specimen, and implicitly their deterioration, permitted the identification of a very intense cellular activity at the level of the implant-tissue interface. Immediately after implantation, the immune response triggered a proliferation of local macrophages.

While erythrocytes are clearly important in oxygen transport (see figure 7), they can reasonably be assumed to be of little importance in the mechanisms of early peri-implant healing. Platelets, however, are of considerable importance since their activation leads to a rearrangement in cell shape and to centralization of storage granules followed by the release of their contents into the extracellular environment (degranulation); and platelet degranulation releases a number of growth factors, such as platelet-derived growth factor (PDGF) and transforming growth factor beta (TGF-b), together with vasoactive factors such as serotonin and histamine. (Davies, 2005). Conventional wisdom holds that these factors play an important role in the regulation of the wound-healing cascade, (Park et al., 2001) based on in vitro and in vivo evidence of their stimulatory effects on the proliferation and migration of various cell types. (Gruber et al., 2002) For example, both PDGF and TGF-b have been shown to be not only mitogenic for fibroblasts but also chemotactic factors for fibroblasts, neutrophils, and smooth muscle cells, (Lucas et al., 1988) as well as osteogenic cells. (Lind, 1998) Indeed, not only has PDGF been shown to stimulate the proliferation of human osteoblasts, (Tsukamoto et al., 1991) but also is able to stimulate the recruitment, migration, and profileration of bone marrow-derived cells. (Oprea et al., 2003) Following platelet degranulation, arachidonic acid metabolites are secreted that cause vasoconstriction. Within the surrounding tissue, factors VII and III (tissue factor) in the extravasated blood cause the activation of factor $\mathrm{X}$ that, together with factor $\mathrm{V}$, causes the conversion of prothrombin to thrombin, which cleaves the fibrinopeptides from fibrinogen to produce the fibrin of the clot (Colman et al., 1987).

Since fibrin, which is the reaction product of thrombin and fibrinogen released into the healing site, can be expected to adhere to almost all surfaces, osteogenic cell migration may be expected towards any implanted material. However, as is well known in dermal wound healing models, connective tissue cell migration is concomitant with wound contraction, which usually begins around the fifth day postwounding. (Peacock, 1984) Indeed, the migration of fibroblasts has been recognized as responsible for wound contraction, with individual cell adhesive contacts transducing a contractile force. (Galbraith et al., 1997) This ability of cells to contract the matrix through which they migrate can be modeled in vitro (Oprea et al., 2003;) and, in the bony peri-implant site could possibly cause retraction of the transitory fibrin scaffold away from the implant surface. The fact that primary osteogenic cells can cause fibrin contraction can be demonstrated by treating primary osteogenic cell cultures with cytochlasin-D, which blocks actin-dependent cell processes, such as cell migration, by capping actin filaments. (Pederson et al., 2001) Thus, the ability of an implant surface to retain fibrin during this wound contraction phase of healing is critical in determining if the migrating cells will reach the former (see figure 8 ). The implant surface design will play an important role in this fibrin retention. (Dumitru et al., 2005) Indeed, if implants are recovered a few days after implantation, the adhesion of this transitory matrix to some surfaces can be easily visualized. (Ciocan et al., 2010) In our research, after a period of several weeks the replacement of the granulation tissue with immature conjunctive (fibrous) tissue begins. 

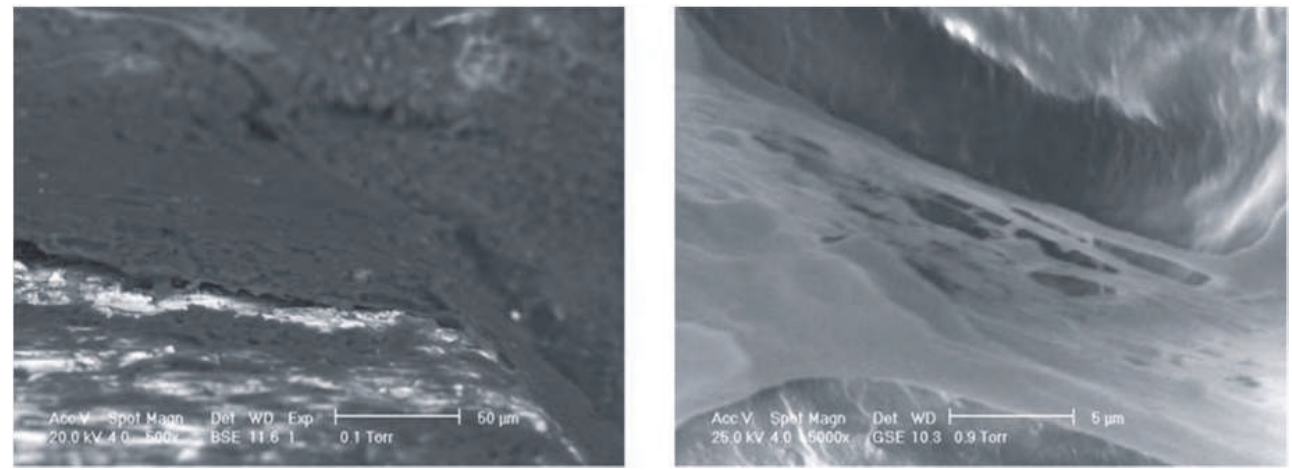

Fig. 8. ESEM images showing replacement of the granulation tissue with the periimplantar fibrous tissue (left) and continuous aspect of connective fibers and fibrocitary intense activity presence (right).

The conjunctive fibers (collagen) form a continuous texture on the implant surface in which there is identified a rich capillary vascularization while the cell population, dominantly of a fibrocitary nature, is much richer in younger elements. The most intense cellular activity was found in the area of biological tissue-implant interface. In the same period, the very first fine trabeculae of neoformation bone begins to appear.

Around endosseous implants, osteoblasts may lay down bone on the old bone surface or on the implant surface itself. This distinction was explored from the early 80 'th as two phenomena, distance and contact osteogenesis, by which bone can become juxtapose to an implant surface. The periimplantar osteogenesis mechanism is still not completely elucidated. According to some authors, for about one month after the implantation, a partial bone marrow necrobiosis phenomenon occurs; similar biological phenomena are taking place for the heterotopy transplants. (Hutchinson, 2005) This mechanism seems to be responsible for the development of inductors, which determine the transformation of the mesenchymal cells from the receptor bed into osteoblasts. This phenomenon was confirmed by the image observations from this study. First, bone matrix is synthesized by only one cell: the osteoblast. While some would argue that osteoblasts from different anatomical sites represent different end members of this osteogenic differentiation pathway, the outcome remains the same: it is the osteoblast that makes bone matrix. Indeed, like most secretory cells, osteoblasts are polarized cells, and the direction of their secretory activity is away from the nuclear end of the cell (this is also true for the so-called reverse polarization of ameloblasts). Since the matrix secreted by osteoblasts becomes mineralized as bone tissue, the cell processes of osteoblasts become surrounded by mineralized matrix (and, with their canaliculi, form the only means of vital communication between surface osteoblasts and those that have become completed surrounded by matrix as osteocytes). Thus the osteoblast is irrevocably attached to the bone-forming surface.

The experimental results obtained have validated also the biomineralization three-phased experimental model described by Urist, 1965. According to this theory, the calcium ion is bounded to a protein in the first phase, it is associated in the second phase with phosphate forming $\mathrm{Ca}-\mathrm{PO}_{4}$ protein complex and finally in the third phase, there takes place the formation of the geometric configuration of a nucleation center. The degree of mineralization of conjunctive matrix around implant was counted by EDAX analisys (see 

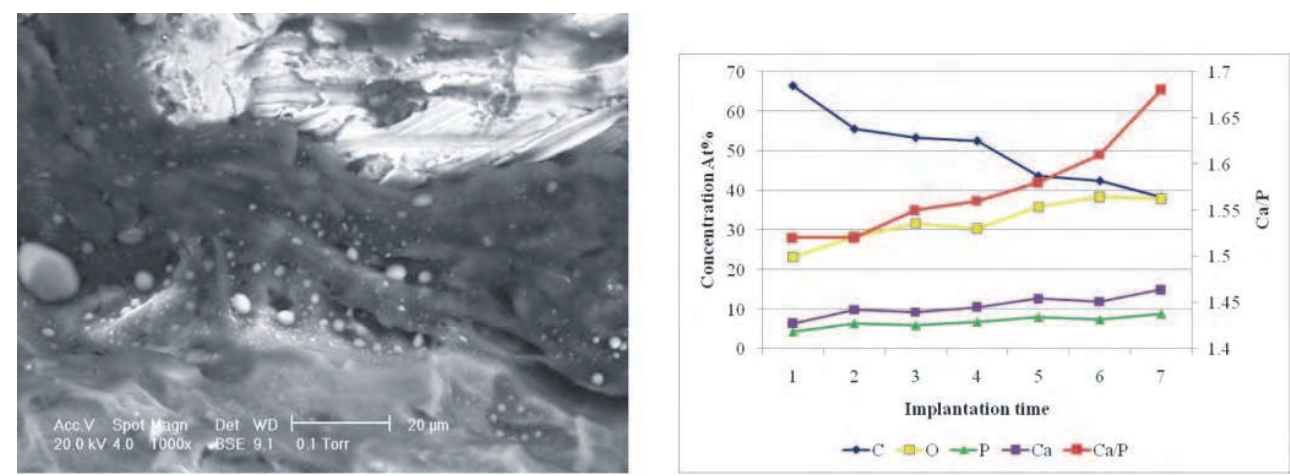

Fig. 9. Periimplantar phosphocalcic precipitations at the level of the vascular walls (left); Basic elements concentration (At\%) variation with time after Ti implant insertion (right).

figure 9). The results of this analysis show the continuous mineralisation of the implant surrounding tissue during 6 month after implantation. This graphics presents the variation of the basic elements from the chemical composition of the bone in the "de novo" tissue that surrounds the titanium implants.

Although the concentration of the mineral elements $(\mathrm{Ca}, \mathrm{P})$ brought at the peri-implant healing site remain similar during time, the hydroxiapatite precipitations are continuous growing in the same time with reduction of organic fibrous tissue (see table 2). The inflection point of the curve appear at the second half of the $3^{\text {rd }}$ month after insertion when the mineral content of the tissue around implant exceeds the organic matrix one. After about two months from the implantation, the periimplantar tissue consists of a conjunctive fibrous tissue rich in cell population, which suffers intense bony neotransformation processes.

\begin{tabular}{|l|l|l|l|l|l|}
\hline Time & $\mathbf{C} \%$ & $\mathbf{O} \%$ & $\mathbf{P} \%$ & $\mathbf{C a} \%$ & $\mathbf{C a} / \mathbf{P}$ \\
\hline 7 days & 66,34 & 23,1 & 4,23 & 6,34 & 1,52 \\
\hline 14 days & 55,48 & 28,33 & 6,4 & 9,79 & 1,52 \\
\hline 1 month & 53,32 & 31,61 & 5,91 & 9,16 & 1,55 \\
\hline 2 month & 52,5 & 30,33 & 6,71 & 10,46 & 1,56 \\
\hline 3 month & 43,66 & 35,76 & 7,98 & 12,6 & 1,58 \\
\hline 4 month & 42,45 & 38,33 & 7,36 & 11,85 & 1,61 \\
\hline 6 month & 38,36 & 37,9 & 8,86 & 14,88 & 1,68 \\
\hline
\end{tabular}

Table 2. Concentration (At\%) of the chemical elements at the implant-bone interface

At four months from the intervention, the periimplantar fibrous tissue is almost disappeared while the newbone has already started the functional remodelling (see figure 10), while after 6 months from the implantation, the newly formed bone is matured and functional remodeled so that the boundaries of the original bony defect can be hardly seen by the help of the electronic microscope (see figure 11).

Intimate biological mechanisms adherence of bone tissue on the surface of the pure titanium implant is cohesively demonstrated by bone substrate. Contact osteogenesis relies upon 
osteoconduction, (Osborn et al., 1980) or the recruitment and migration of differentiating osteogenic cells to the implant surface, together with "de novo" bone formation by those cells on the implant surface. Osteoconduction also occurs during normal tunneling remodeling in bone. In such remodeling, differentiating osteogenic cells are derived from undifferentiated peri-vascular connective tissue cells (pericytes), just as soft tissue fibroblasts have long been recognized as being derived from the mesenchymal cell populations of blood vessel adventia. (Ross et al., 1970) However, a more complex environment characterizes the peri-implant healing site.
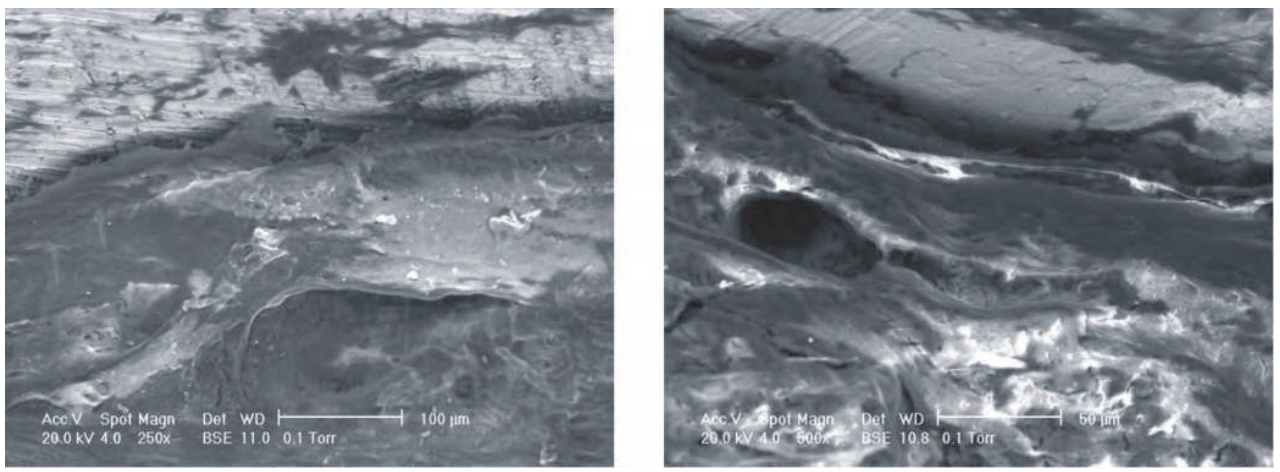

Fig. 10. Periimplantar fibrous tissue transformed into neoformation bony tissue after 3 month (left); after 4 month (right).
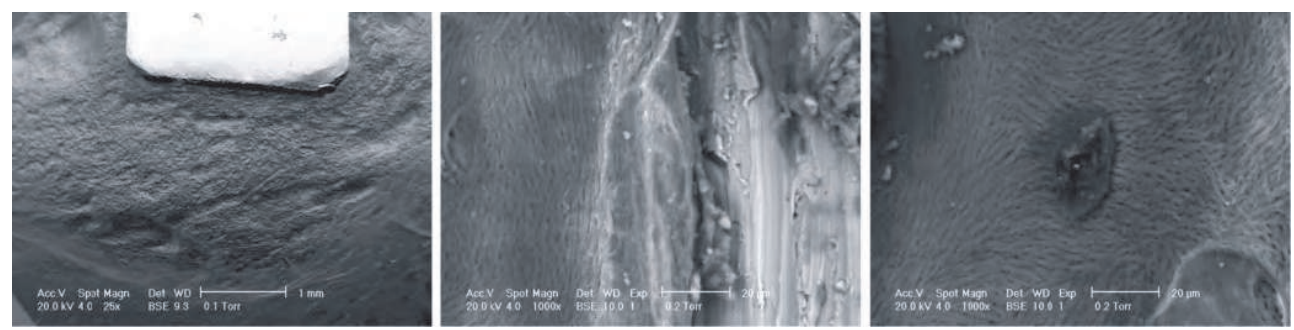

Fig. 11. ESEM macrography at 6 month- periimplantar new bone tissue in the full process of functional remodelling: left - bone wound healed around implant; center - mature bone connected to implant; right - osteon formatted in the periimplant new bone.

\subsubsection{Osseointegration according to the roughness of the implant surface}

Every samples was analyzed by electron microscopy (ESEM), using secondary electron detector in water vapor environment (GSE), retro scattered electron detector (BSE), respectively by qualitative and quantitative compositional analysis EDAX type. During the analysis by electron microscopy ESEM, it was identified the roughness of the surface, periimplantary hiatus sizes and periimplantary vascular plexus. It was also observed the thickness of the periimplantary fibrous callus under calcification and the morphology of the bone tissue neoformation (see figure 12). During an analysis of the sample of Ti6Al4V alloy under axial incidence, it was macroscopic (X20) noticed both filling the periimplantary 
defect with neoformation bone tissue and covering the implant with this one, on some areas. Afterwards, the bone implant interface was examined on each side of the sample.
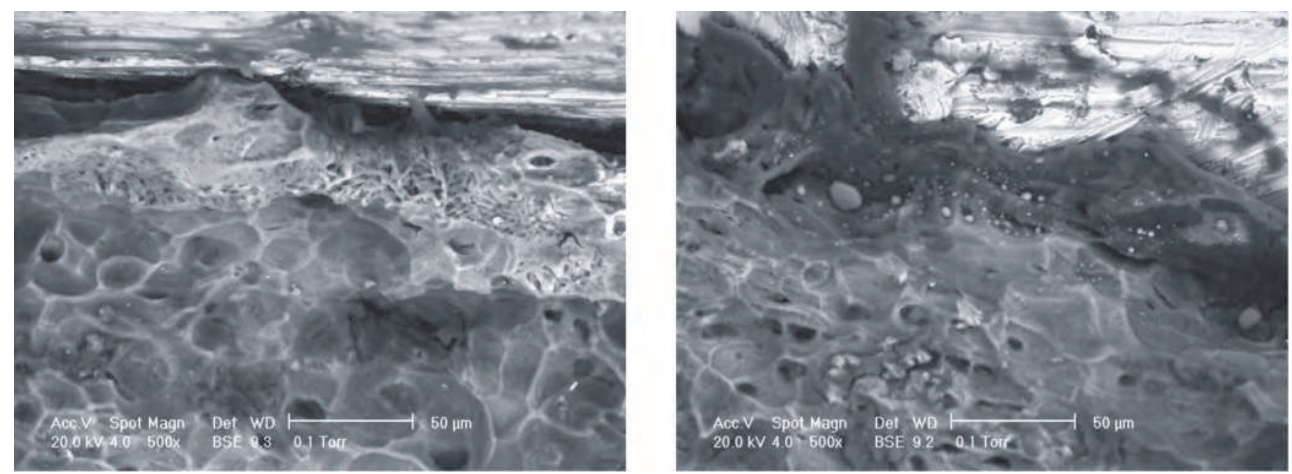

Fig. 12. Interface morphology of newly formed bone and the face 1 of the implant (left), and face 2 , respectively (right).

The ESEM imaging identifies roughness surfaces. If training with roughness P600, the periimplantary hiatus has small dimensions, $5 \mu \mathrm{m}$ on average, the vascular plexus being absent. It is also noticed the lack of the fibrous tissue. The new formation of bone tissue presents a remodeling aspect. The surface roughness at this level (P320) (side 2) was the determining factor of the maximum neo-bony adhesion for this implant. However, the mineralization processes of the protean organic matrix are delayed from those presented in the side 1 .
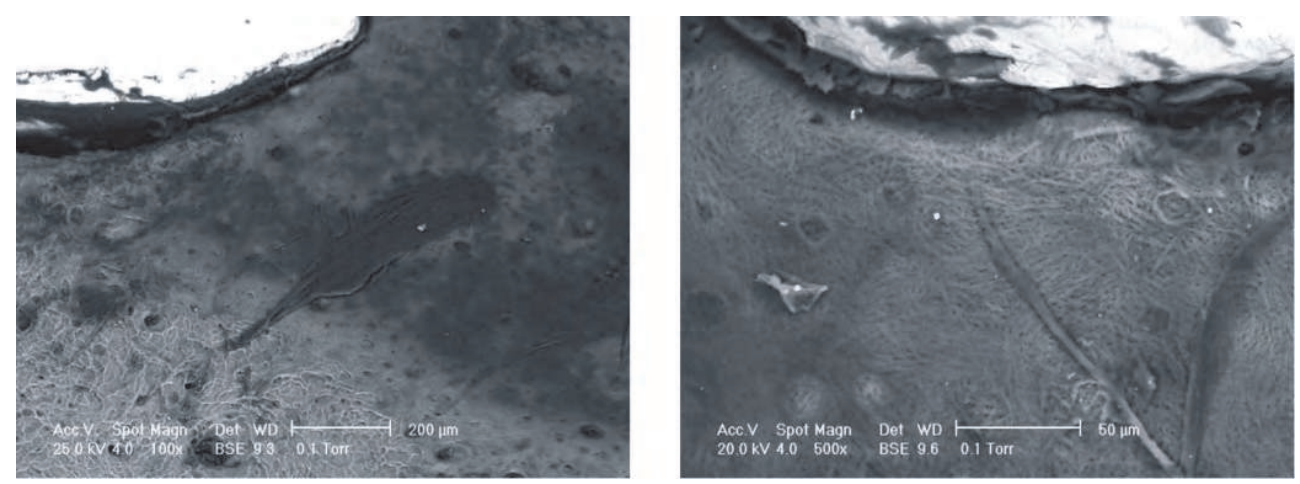

Fig. 13. Interface morphology of newly formed bone and the face 3 of the implant (left), and face 4 , respectively (right).

At a roughness obtained with P1000 paper (face 3), on the periimplatary hiatus of $15 \mu \mathrm{m}$ large dimension, it is noticed the presence of a rich vascular plexus (see figure 13). The neoformation bone tissue presents Havers large and remote channels. At a roughness obtained with P800 paper (face 4), the hiatus is $10 \mu \mathrm{m}$, periimplementary, being observed the presence of uncalcifying fibrous tissue, with thickness of 20 to $25 \mu \mathrm{m}$. The image captures vascular axis of some Havers collateral channels. 


\section{Conclusion}

In the context of the complexity of implant surfaces, due to the different structures and theirs roughness, also to different chemical compositions, the purpose of this study was to examine the processes of tissue implant interface. To achieve this desideratum, I performed, in this order, determinations regarding the biomaterials' microstructure, their resistance to the corrosion, their behavior and influence above the cellular cultures and, finally, in vivo tests on animals. I approached the interaction of implants made of metal biomaterials, with different structures and the surface roughness, with biological tissues, which included discussions on the mechanism of implants' incorporation and on the development and changes of living tissues during remodeling after insertion.

The surfaces of different implants were measured and compared to the bone surface, as it is known that these surfaces are covered, in many cases, with new bone deposits and therefore they serve as fixing points for newly formed bone. The structures' surfaces of the implants were characterized, measured and correlated to the morphometrical evaluations of the tissue - biomaterial contact.

By using cell culture techniques, it can cause lyses (death) of cells, cell growth inhibition, and some specific effects on cells caused by the devices, materials and / or their extracts. The percentage of the growth inhibition was determined by counting cells, and the measurements were corrected for control with a negative filter. As a reference experiment, we took a fibroblast culture in which no metallic sample was immersed, the culture being kept under the same conditions of the experiments in which were immersed metallic samples. It may be noted that a cellular monolayer was obtained, at all the studied experiments, without being registered any free spaces, in which fully lack the cellular culture. After analyzing the obtained images, it may be presented some important characteristics of the studied cellular cultures. In the case of the cellular culture without metallic sample (blank), the fibroblast cells of the culture highlight morph-structural fairly uniform characteristics. Covering the well with cellular formation is about $90 \%$. It is obviously the cells' compaction and the appearance of the phenomenon of forming a multilayer culture. Finally, depending on the studied biomaterial type, we obtained the monolayer formation ranged from 90 to $55 \%$ of the surface, in some cases being noticed the pluristratification trend. The main indicators taken into account under the regulations existing standards were: cells' number, proliferation, cell adhesion to the substrate, cells' viability. The cellular culture system appears to be sensitive to the in vitro evaluation of metallic biomaterials with cells interactions and cellular response features. The experimental models, developed for investigations on cellular cultures, have been based on the overall assessment and namely that the cellular culture system is a useful means for testing the biomaterials' cytotoxicity and helps to reduce the experiments' number on animals.

The in vivo experimental study on animals regarding the interactions of the biomaterialtissue interface showed that, whatever the samples' type was, it was macroscopically and microscopically found the bio-integrity of all implants. The speed of transforming the periimplantary fibrous tissue into a neo-differentiated bone tissue, respectively the "calcification" of the periimplantary fibrous tissue was significantly higher in terms of quality and quantity for the samples on which hydroxyapatite has been filed.

The observed and described imagistic elements allowed the real appreciation of the influence of metal surface preparation method on the bio-integrity complex process. For none of the samples were observed periimplantary osteolysis processes, which proves the 
existence of a favorable interaction between the implanted biomaterial and the biological structure (bone tissue). Whatever the implant type, it was noticed a direct proportionality between the preparation degree of implant surface (mechanical preparation, blasting, chemical attack) and the degree and speed of transforming the periimplantary tissues into mature bone tissue (tissue neoformation inflammatory vascular plexus, fibrous tissue, bone tissue neoformation). The development and periimplantary organic matrix mineralization degree was closely correlated with biochemical changes at the interface. The neoformation bone tissue was intensely mineralized in the case of pure titanium implant, less mineralized in the case of the TiAl64V implant, poorly mineralized for the implantation of Co-Cr-Mo and scarcely mineralized for stainless alloy implant.

By the help of the scan electronic microscopy, using an ESEM XL 30 electronic microscope, it was possible the observation and standardization of the biointegration processes from the interface of the titanium implants. The images presented, show the intimate evolution of the healing processes from this level and represent the fundamental base for the theory for the metallic implant osseointegration.

This study made possible the understanding of the intimate cellular and tissue bony integration mechanisms of the titanium metal implants. A few days after the implantation, a proliferation of two types of cells become visible: the fibroblasts that will form a periimplantar fibrous callus and endothelial cells that will generate a capillary network of neoformation observed by ESEM as a periimplantar vascular plexus. Through the processes of proliferation of fibroblasts and vascular endothelium, the periimplantar clot is replaced by granulation tissue during 7 days from the surgical procedure. At the same time, a process of osseoclastic resorption at the edges of bone defect begins. In two weeks, around implant it will be developed an immature conjunctive fibrous tissue. After about two months from the implantation, the periimplantar tissue consists of a conjunctive fibrous tissue rich in cell population, which suffers intense bony neotransformation processes. At four months, the periimplantar fibrous tissue is almost disappeared while the newbone has already started the functional remodelling. In 6 months from the implantation moment, the newly formed bone is matured and functional remodelled so that the boundaries of the original bony defect can be hardly seen by the help of the electronic microscope.

Based on image observations for the surrounding tissues unaffected by the experiment, the validation of the results obtained was possible. The degree of mineralization of conjunctive matrix around implant was counted by EDAX analysis. Our results showed that the concentration of the mineral elements $(\mathrm{Ca}, \mathrm{P})$ brought at the peri-implant healing site remain similar during time, while hydroxiapatite precipitations are continuous growing and organic fibrous tissue is reducing. The inflection point of the curve appear at the second half of the $3^{\text {rd }}$ month after insertion when the mineral content of the tissue around implant exceeds the organic matrix one.

There are still many aspects of peri-implant healing that need to be elucidated. According to the authors, there should be rigorously investigated further the chemical-enzymatic mechanisms underlying the osseointegration biological processes.

\section{Acknowledgment}

This work was supported by CNCSIS-UEFISCSU (UEFISCDI); project number PN II-RU $104 / 2010$. 


\section{References}

Anselme K, Bigenelle M, Noel B, Dufresne E, Judas D, Iost A, Hardouin P., 2000, Qualitative And Quantitative Study Of Human Osteoblast Adhesion On Materials With Various Surface Roughnesses, Journal of Biomed Mater Res, 49, pp. 155-166.

Black J., 1992, Biological Performance of Materials: Fundamentals of Biocompatibility, 2nd ed., Marcel Dekker, ISBN 0-82-478439-1;

Branemark PI, Chien S, Grondahl HG, Robinson K., 2006, The Osseointegration Book: From Calvarium to Calcaneus, Quintessence Publishing, ISBN 1850970904.

Brodbeck WG, Shive MS, Colton E, Nakayama Y, Matsuda T, Anderson JM., 2001, Influence Of Biomaterial Surface Chemistry On The Apoptosis Of Adherent Cells, Journal of Biomedical Mater Res., 55, pp. 661-668.

Ciocan LT, Miculescu F, Miculescu M, Patrascu I., 2010, Retrieval analysis on dental implants biointegration phases, Romanian Journal of Morphology and Embryology, 51, pp. 117-122.

Colman RW, Marder VJ, Salzman EW, Hirsh J. Overview of hemostasis. In: Colman RW, Hirsh J, Marder VJ, Salzman EW, eds., 1987, Hemostasis and thrombosis/basic principles and clinical practice, 2nd ed. Philadelphia: Lippincott, pp. 3-17.

Cormack DH., 1987, Bone. In: Ham's histology, 9th ed. Philadelphia: Lippincott, pp. 273-323.

Davies JE, 2005, Understanding Peri-Implpant Endosseous healing, J Dent Edu, Re-issued in Transfer of Advances Sciences into Dental Education, Toronto: Em squared Inc., 67, pp. 932-949.

Dekker A, Panfil C, Valdor M, Pennartz G, Richter H, Mittermayer Ch, Kirkpatrick CJ., 1994, Quantitative Methods For In Vitro Cytotoxicity Testing Of Biomaterials, Cells Mater., 4, pp.101-112.

Dumitru N, D. Bunea D, Patrascu I, Ciocan LT, F. Miculescu F., 2005, Chemical Composition and Surface Preparation Level Influence on Metallic Implants Biointegrability, European Cells and Materials, 9, pp. 27-28.

Futami T., Fujii N., Ohnishi H., Taguchi N., Kusakari H., Ohshima H., Maeda T., 2000, Tissue Response To Titanium Implants In The Rat Maxilla: Ultrastructural And Histochemical Observations Of The Bone-Titanium Interface, Journal of Periodontol, 71, pp. 287-298.

Galbraith CG, Sheetz MP., 1997, A micromachined device provides a new bend on fibroblast traction forces. Proc Natl Acad Sci USA, pp. 9114-9118.

Gruber R, Varga F, Fischer MB, et al., 2002, Platelets stimulate proliferation of bone cells: involvement of platelet-derived growth factor, microparticles and membranes, Clin Oral Impl Res, pp. 529-535.

Hazan, R., Brener, R., and Oron, U., 1993, Bone Growth To Metal Implants Is Regulated By Their Surface Chemical Properties, Biomaterials, 14, pp. 570-574.

Hutchison J., 2005, The fate of experimental bone autografts and homografts, British Journal of Surgery, 39, pp. 552-561.

Ilin A.A., Skvortsova S.V., 2002, Titanium and Titanium Alloys, Effect of Thermohydrogen Treatment on the Structure and Properties of Titanium Alloy Castings, Metal Science and Heat Treatment, 44, pp. 5-6. 
Kasemo B \& Lausmaa J., 1991, The Biomaterial-Tissue Interface And Its Analogues In Surface Science And Technology, In Davies JE (editor) The bone-biomaterial interface, University of Toronto press, Toronto, pp. 19-32.

Kilburn M.R., Lewis A., Papageorgiou I., Allen G.C., Case C.P., 2003, Surface Characterization And Matal Ion Release From CoCr Alloy Used In Orthopaedic Implants, Proceeding of 18th European Conference on Biomaterials.

Kocijan A., Milosev I., Merl D.K., Pihlar B., 2004, Electrochemical Study Of Co-Based Alooys In Simulated Physiological Solution, Journal of Applied Electrochemistry, pp. 7.

Lakey L, Akella R, Ranieri JP, 2000, Angiogenesis: implications for tissue repair. In: Davies JE, ed. Bone engineering. Toronto: em squared Inc., pp. 137-142.

Lind M., 1998, Growth factor stimulation of bone healing: effects on osteoblasts, osteomies, and implant fixation, Acta Orthop Scand Suppl., pp. 283:2-37.

Lucas PA, Caplan AI., 1988, Chemotactic response of embryonic limb bud mesenchymal cells and muscle-derived fibroblasts to transforming growth factor-beta. Connect Tissue Res, 18, pp. 1-7.

Matsuo M, Nakamura T, Kishi Y, Takahashi K., 1999, Microvascular changes after placement of titanium implants: scanning electron micrscopy observations of machined and titanium plasma-sprayed implants in dogs, J. Periodontol, 70, pp. 1330-1338.

Miculescu F, Bojin D, Ciocan LT, Antoniac I, Miculescu M, Miculescu N., 2007, Experimental researches on biomaterial-tissue interface interactions, Journal of Optoelectronics and Advanced Materials; 9, pp. 3303-3306.

Moiseev V.N., 2004, Titanium Alloys-Structural Titanium Alloys in Modern Mechanical Engineering, Metal Science and Heat Treatment, 46, pp. 3-4.

Murakami I., 1995, Scanning electron microscopic study on bone and microvasculature surrounding titanium implants, J Jpn Prosthodont Soc; pp. 123-134.

Oprea WE, Karp JM, Hosseini MM, Davies JE. 2003, Effect of platelet releasate on bone cell migration and recruitment in vitro, J Craniofac Surg, 14, pp. 292-300.

Osborn JF, Newesely H., 1980, Dynamic aspects of the implant-bone interface. In: Heimke G, ed. Dental implants: materials and systems. Muunchen: Carl Hanser Verlag, pp. 111123.

Park JY, Gemmell CH, Davies JE., 2001, Platelet interactions with titanium: modulation of platelet activity by surface topography, Biomaterials, 22, pp. 2671-2682.

Peacock EE., 1984, Wound repair. In: Peacock, EE, ed. Wound repair. Philadelphia: Saunders, pp. 38-55.

Pederson SF, Hoffmann EK, Mills JW., 2001, The cytoskeleton and cell volume regulation. Comp Biochem Physiol A Mol Integr Physiol, 130, pp. 385-399.

Puleo, D.A. and Nanci, A., 1999, Understanding And Controlling The Bone-Implant Interface, Biomaterials, 20, pp. 2311-2321.

Ross R, Everett NB, Tyler R., 1970, Wound healing and collagen formation: VI. The origin of the wound fibroblast studied in parabiosis, J Cell Biol, 44, pp. 645.

M.D. Smith, J.C. Barbenel, J.M. Courtney, M.H. Grant, 1992, Novel quantitative methods for the determination of biomaterial cytotoxicity, International Journal of Artificial Organs, 15, pp. 191-194. 
Stanford C.M., Schneider G., Keller J.C., Midura R., 2003, Biomedical Implant Surface Topography And Its Effects On Osteoblast Differentiation, Bio-implant interface Improving biomaterials and tissue reactions, pp. 141-164, ISBN 0-8493-1474-7.

Tsukamoto T, Matsui T, Fukase M, et al., 1991, Platelet-derived growth factor B chain homodimer enhances chemotaxis and DNA synthesis in normal osteoblast-like cells (MC3T3-E1), Biochem Biophys Res Commun, 175, pp. 745-751.

Urist MR., November 1965, Bone: Formation by autoinduction, Science, 150, pp. 893 - 899.

Wennerberg A., Ide-Ektessabi A., Hatkamata S., Sawase T., Johansson C., Albreksson T., Martinelli A., Sodervall U., Odelius H., 2003, Titanium Release From Implants Prepared With Different Surface Roughness- An in vitro and ex vivo study, Proceeding of $18^{\text {th }}$ European Conference on Biomaterials.

Yan, W., Nakamura, T., Kobayashi, M., Kim, H., Miyaji, F., Kokubo, T., 1997, Bonding Of Chemically Treated Titanium Implants To Bone, Journal of Biomed. Mater. Res., 37, pp. 267-275. 


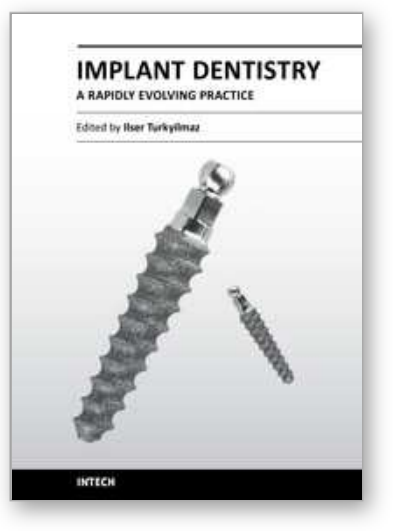

\author{
Implant Dentistry - A Rapidly Evolving Practice \\ Edited by Prof. Ilser Turkyilmaz
}

ISBN 978-953-307-658-4

Hard cover, 544 pages

Publisher InTech

Published online 29, August, 2011

Published in print edition August, 2011

Implant dentistry has come a long way since Dr. Branemark introduced the osseointegration concept with endosseous implants. The use of dental implants has increased exponentially in the last three decades. As implant treatment became more predictable, the benefits of therapy became evident. The demand for dental implants has fueled a rapid expansion of the market. Presently, general dentists and a variety of specialists offer implants as a solution to partial and complete edentulism. Implant dentistry continues to evolve and expand with the development of new surgical and prosthodontic techniques. The aim of Implant Dentistry - A Rapidly Evolving Practice, is to provide a comtemporary clinic resource for dentists who want to replace missing teeth with dental implants. It is a text that relates one chapter to every other chapter and integrates common threads among science, clinical experience and future concepts. This book consists of 23 chapters divided into five sections. We believe that, Implant Dentistry: A Rapidly Evolving Practice, will be a valuable source for dental students, post-graduate residents, general dentists and specialists who want to know more about dental implants.

\title{
How to reference
}

In order to correctly reference this scholarly work, feel free to copy and paste the following:

Lucian Toma Ciocan, Florin Miculescu, Marian Miculescu and Ion Patrascu (2011). Biological Reactions to Dental Implants, Implant Dentistry - A Rapidly Evolving Practice, Prof. Ilser Turkyilmaz (Ed.), ISBN: 978-953307-658-4, InTech, Available from: http://www.intechopen.com/books/implant-dentistry-a-rapidly-evolvingpractice/biological-reactions-to-dental-implants

\section{INTECH}

open science | open minds

\section{InTech Europe}

University Campus STeP Ri

Slavka Krautzeka 83/A

51000 Rijeka, Croatia

Phone: +385 (51) 770447

Fax: +385 (51) 686166

www.intechopen.com

\section{InTech China}

Unit 405, Office Block, Hotel Equatorial Shanghai

No.65, Yan An Road (West), Shanghai, 200040, China 中国上海市延安西路65号上海国际贵都大饭店办公楼 405 单元

Phone: +86-21-62489820

Fax: +86-21-62489821 
(C) 2011 The Author(s). Licensee IntechOpen. This chapter is distributed under the terms of the Creative Commons Attribution-NonCommercialShareAlike-3.0 License, which permits use, distribution and reproduction for non-commercial purposes, provided the original is properly cited and derivative works building on this content are distributed under the same license. 